\title{
Designing gamification for geometry in elementary schools: insights from the designers
}

\author{
Vimala Judy Kamalodeen ${ }^{{ }^{*}}$,, Nalini Ramsawak-Jodha', Sandra Figaro-Henry ${ }^{2}$, Sharon J. Jaggernauth ${ }^{1}$ and \\ Zhanna Dedovets ${ }^{1}$
}

*Correspondence:
vimala.
kamalodeen@gmail.com;
vimala.kamalodeen@sta.
uwi.edu
${ }^{1}$ School of Education, The
University of the West Indies,
Gordon Street, St. Augustine,
Trinidad and Tobago
Full list of author information
is available at the end of the
article

${ }^{*}$ Correspondence:

vimalakamalodeen@sta.

uwi.edu

${ }^{1}$ School of Education, The University of the West Indies, t. Augustine,

Full list of author information article

\begin{abstract}
Popularly used in marketing and business, gamification has been gaining interest in educational contexts for its potential to invigorate otherwise mundane or difficult processes. A gamified environment transfers motivational elements of games to learning activities thereby engaging learners in the learning task thus transforming dull classroom environments to smart ones. This paper presents the design process of a gamification intervention in geometry at elementary level, based upon Huang and Soman (Gamification of education. Research report series: behavioural economics in action, 29. Rothman School of Management, University of Toronto, Toronto, 2013) model. We describe how insights from various sources helped us to refine an intervention previously used in one school. The design focuses on gamifying the tangram, an unplugged resource, through incorporating game-based elements of leader boards, points/stars and challenge levels to motivate young learners individually and in teams. Cognitive and motivational scaffolding undergird five challenge levels to bring affordances to self and social elements for learner participation in increasingly complex geometry tasks. There are limited theoretical models to guide educational researchers, especially ones that do not require digital resources. This paper presents our insights and recommendations to support scaffolded learning in student-centred gamified learning environments.
\end{abstract}

Keywords: Gamification design, Elementary mathematics, Geometry, Scaffolding, Unplugged resources, Smart learning environments, Researcher insights

\section{Introduction}

Due to its growing popularity as an emerging pedagogical approach in the educational domain (Baldeón et al., 2015; Kapp, 2012; Nand et al., 2019; Stoyanova et al., 2016), greater attention to designing gamification interventions is necessary for creating smart learning environments. Studies on gamification often present students' perspectives on and results of using a gamification intervention in classroom settings (such as Kimble, 2020; Udjaja et al., 2018), rather than insights on conceptualising and designing processes related to implementing gamification (Dichev \& Dicheva, 2017; Hung et al., 2017). While gamification is appealing across many disciplines, careful attention to its

(c) The Author(s), 2021. Open Access This article is licensed under a Creative Commons Attribution 4.0 International License, which permits use, sharing, adaptation, distribution and reproduction in any medium or format, as long as you give appropriate credit to the original author(s) and the source, provide a link to the Creative Commons licence, and indicate if changes were made. The images or other third party material in this article are included in the article's Creative Commons licence, unless indicated otherwise in a credit line to the material. If material is not included in the article's Creative Commons licence and your intended use is not permitted by statutory regulation or exceeds the permitted use, you will need to obtain permission directly from the copyright holder. To view a copy of this licence, visit http:// creativecommons.org/licenses/by/4.0/. 
use in educational contexts is important if it is to become a recognized instructional approach (Dichev \& Dicheva, 2017; Smiderle et al., 2020). However, knowledge of how to gamify an intervention for educational contexts is limited yet important for researchers and practitioners alike. Gamification interventions offer opportunities to engage the learner during the learning process (Pesare et al., 2016), thus creating smart learning environments.

We define gamification as "using game-based mechanics, aesthetics and game thinking to engage people, motivate action, promote learning, and solve problems" (Kapp, 2012, p. 125) in "non-game contexts" (Deterding et al., 2011, p. 1). Gamification is the practice of using "game elements or functionalities such as points, rewards, tasks, challenges, goals or immediate feedback for learning purposes" (Lämsä et al., 2018, p. 598). Gamification fosters a playful or gameful attitude, which may benefit learning, but differs from play. When learners play and play games, these activities aid in developing cognition, social processes, motivation and foundational mathematics skills, (D'Angour, 2013; Wiersum, 2012). Neither play nor playing games, however, contain all the elements and functionalities as those exemplified in gamification. Research provides evidence that gamification can have positive outcomes in mathematics (e.g., Baldeón et al., 2015; Stoyanova et al., 2017) and supports learner engagement and achievement in geometry specifically (see Aridi \& Saad, 2020; [Authors]).

Over time, there have been numerous challenges in teaching and learning mathematics (Clements, 2004; Duru, 2010; Hodara, 2011; Jones, 2002; Rouadi, 2014; Siew et al., 2013). Traditional approaches have not been able to address the growing challenge of learner disengagement in studying mathematics. Teachers struggle to find appropriate instructional strategies in geometry (Sunzuma \& Maharaj, 2019). Geometry is a strand that focuses on geometric thinking and visualization-key transferable skills. Strong links are found between teachers' instructional strategies and students mathematics proficiency (Hodara, 2011). Strong links also exist between active approaches that develop students' competence to enhance their performance (Duru, 2010; Patadia, 2016; Takele, 2020). In geometry, recommendations are made for an early start at elementary level and the use of active pedagogies (see Salifu et al., 2018). These challenge educational researchers to find ways to use novel pedagogies and approaches to transform the dull learning environments in mathematics classrooms to smart ones.

As an alternative to traditional pedagogies, active learning pedagogies such as games, can be beneficial to students (Nand et al., 2019; Ting et al., 2019). Salen and Zimmerman (2004) succinctly defined games as systems where players engage in an artificial conflict, their actions are defined by rules, and the consequence of playing the game is a quantifiable outcome. The player has an emotional attachment to the outcome, and the results of the activity are negotiable (Juul, 2005). Gamified learning incorporates game elements to enact game-like experiences to accomplish predefined goals which impact positively on learners' motivation (Dichev et al., 2020). Two approaches to introducing games into mathematics classrooms are game-based learning and gamification, both engaging students in playful explorations of mathematical concepts (Aridi \& Saad, 2020; Baldeón et al., 2015).

We focused on designing a gamification intervention to transform the learning environment in elementary geometry. First, we conducted a pilot study at one school with 
Tangrams and origami at Grade 6. Following analysis of pilot data from teachers and students, we reflected on the initial design and refined it using Huang and Soman's (2013) five step model. The research team used group ideation and discussion to produce a list of key game elements and functionalities of the gamification to engage elementary students cognitively and motivate them to succeed (Nand et al., 2019). One key decision was to continue to use unplugged approaches, particularly to appeal to diverse learners (Huang \& Looi, 2021) and provide young learners with more concrete experiences (Saxena et al., 2020). Unplugged approaches, which have proliferated in recent times in computational thinking, do not use computers, in other words are not technology-based (Huang \& Looi, 2021). As such, this study focuses on gamification of a tangible resourcethe tangram- and is supported by Saxena et al's (2020) work that suggest that unplugged resources can aid mastery of cognitive concepts in young children and provide costeffective interventions.

In this non-empirical paper, we present the key decisions and insights that guided designing the intervention for the main study. We begin by examining the relevant literature on geometric thinking and gamification, presenting a conceptual framework of social constructivism and scaffolding, followed by a brief outline of methods. We then present in detail, the application of Huang and Soman's five steps to designing the intervention, ending with conclusions and recommendations.

\section{Literature review}

\section{Geometric thinking at the elementary level}

Geometry is an important area of mathematics because it develops students' spatial sense and geometric thinking. The challenges experienced in teaching geometry at elementary level can be related to students' individual cognitive and affective development, and teachers' selection and application of instructional strategies, learning activities and resources aligned with levels of student thinking (Clements, 2004; Jones, 2002). van Hiele's (1999) levels of thinking continue to be valuable in developing geometric thinking and proposes that individuals progress through five levels of geometric thinking from being able to recognise shapes to abstraction of visual images and real models (see Fig. 1). The use of manipulatives during early learning of geometry allows students to

\section{Van Hiele's (1999) Levels of Geometric Thinking}

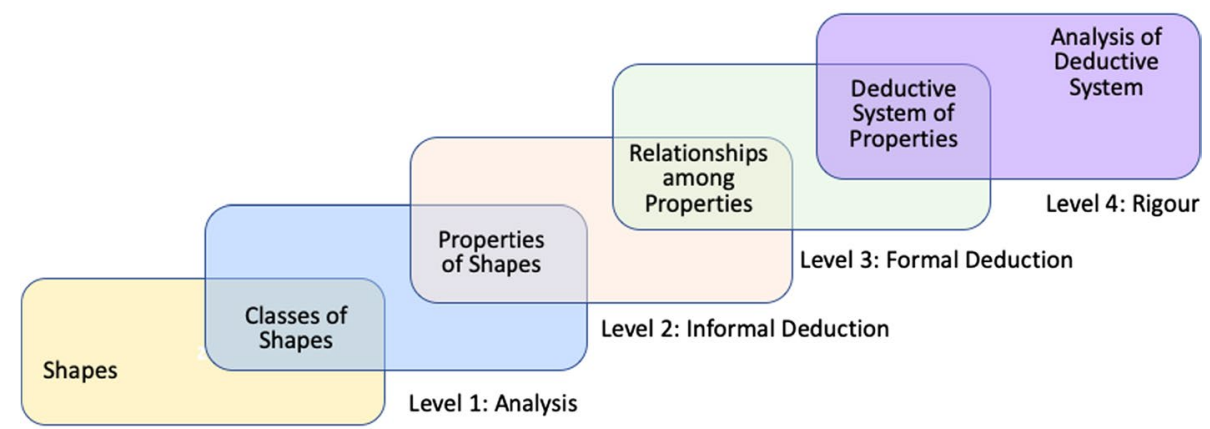

Level 0: Visualisation

Fig. 1 Van Hiele's (1999) Levels of Geometric Thinking 
touch, move, rotate, flip, combine and rearrange shapes and can support their progress through van Hiele's levels (Fuys et al., 1988). Elementary school students' success with geometry requires their teachers to identify at which level they are thinking and design instruction to scaffold their progress from one level to the next, reducing students' reliance on the teacher within the zone of proximal development (ZPD) (Vygotsky, 1978). Progressing through each level requires mastery of previous levels.

van Hiele's (1999) Level 0 (visualisation) is foundational to all levels (Jones, 2002). Van Hiele suggested that students' thinking relies on visual observation for identifying, naming, and recognising shapes without explaining their properties. Students pay attention to how shapes look. For example, students may recognise a rectangle because it resembles a door. They may recognise a square but differentiate it from a rhombus because they have trouble recognising the shape when it is rotated as it does not resonate with their definition of a square. This occurs because of poor conceptual development. At Level 1 (analytical), students can identify, describe, and explain parts and properties of shapes using appropriate language, but cannot yet identify important relationships between properties of different shapes. For example, they can recognise that parallelograms and rectangles have equal and parallel opposite sides, but do not recognise the rectangle as a parallelogram because relationships between concepts are not reinforced. At Level 2 (informal deduction), students can recognise the relationships between shapes and their properties and classify shapes in this way. For example, logical reasoning can be used to explain why a square is a rectangle, but a rectangle is not a square. Students' however have trouble with this due to underdeveloped reasoning skills (Fuys et al., 1988; Salifu et al., 2018; Siew et al., 2013).

The use of manipulatives to support student learning is well documented in the literature (e.g., Boggan et al., 2010; Ojose \& Sexton, 2009; Wiersum, 2012). Using manipulatives to help elementary students transition from concrete to the abstract mathematical thinking is also well established (e.g., Moyer, 2001; Sarama \& Clements, 2009). Tangrams are useful for developing students' geometric skills (Russell \& Bologna, 1982; Siew et al., 2013; Tchoshanov, 2011); its constituent pieces, tans, have both visual and tactile appeal and learners can manipulate them through hands-on experiences. Additionally, tans as unplugged resources, can add to teachers' basket of strategies to promote mental modeling, thus engaging learning in cognitive tasks (Looi et al., 2020). Sarama and Clements (2009) recommend their use in well-planned instructional settings and not just for play. The active manipulation of tans, therefore, can allow for visualization, analysis and deductive reasoning, and developing young learners' spatial sense and geometric thinking.

\section{Gamification for learning mathematics}

Gamification offers the use of game design elements in contexts not usually considered as fun and can transform "dry, discouraging school subjects" such as mathematics (Aridi \& Saad, 2020, p. 1) into interesting ones. These authors suggest that gamification of geometry with elementary students improved students' achievement levels with sustained engagement in learning. Several gamification initiatives are found in the literature related to elementary mathematics (such Aridi \& Saad, 2020; Baldeón et al., 2015; Kimble, 2020) and at other education levels (see Faghihi et al., 2014; Lämsä et al., 2018; 
Rincon-Flores et al., 2018; Wiersum, 2012). However, literature on gamification in education contexts often allude to the inconclusive relationship between student engagement and achievement. What is known, however, is that gamification invokes the same physiological experiences as games such as pleasure and fun (Deterding, 2012). Further, a gamified environment transfers social elements of games to learning activities that develop skills such as communication, sharing, goal setting (Landers \& Callan, 2011), engagement, interactivity, and problem solving (Kapp, 2012). Pedagogical components of gamification include motivation, engagement, learning, thinking and problem solving thus situating this pedagogical innovation within educational contexts. Like educational games, gamification allows for combining "concentration demanded by challenging activities and the enjoyment experienced when maximally utilizing one's skills" (Hamari et al., 2016, p. 171). If designers build out concepts "in steps" to aid cognitive development (Aridi \& Saad, 2020; Faghihi et al., 2014), then challenges within a gamification framework can increase the attractiveness of the learning environment and promote learner engagement (Rincon-Flores et al., 2018).

\section{Gamification and scaffolding}

Vygotsky's (1978) ZPD is a process that scaffolds learning from fully supported by an instructor to independent problem-solving; temporary external supports are removed once learning has been achieved (van Geert \& Steenbeek, 2005). Cognitive scaffolds guide students through using tools and resources to engage in learning activities, organize their ideas and thoughts, and determine strategies they need for monitoring and evaluating their learning (Hannafin et al., 1999; Stavredes \& Herder, 2014). Scaffolding is effective when teachers understand how much of it to apply, when to begin scaffolding and when to disengage, so learning becomes more learner directed (Dabbagh, 2003; Xiang et al., 2014). Motivational scaffolds provide learners with tasks connected to intrinsic motivation (Belland et al., 2013), and are supported by students reflecting on their learning and making necessary adjustments to enhance expectancy for success.

Social constructivist theory (Vygotsky, 1978) emphasises the role of social interactions in contributing to learning through joint construction of knowledge and goal accomplishment. Scaffolds deployed during collaborative tasks allow students to interact with each other and their teachers and share skills and knowledge to expand learning boundaries (van Geert, \& Steenbeek, 2005). Collaborative learning activities, such as team games, support the learning process (Sumtsova et al., 2018); they can facilitate positive feelings because there is a social responsibility to other members of the group, common goals, and belief in group achievement (Deci \& Ryan, 2000). Scaffolding has been applied in gaming environments to teach and reinforce mathematical concepts and skills (e.g., Faghihi et al., 2014; Plass et al., 2015). Hence, gamification that employs scaffolds can increase motivation to learn and promote desired learning behaviours and outcomes.

Teachers must move away from traditional teaching to a new teaching approach such as gamification that develop the student's own thinking. This approach, as catered for in our design, can be supported by flexible and dynamic scaffolding which can respond to each student in the social group (Cobb et al., 2012). Teachers can scaffold learning in the ZPD by using appropriate hints and clues as students progress through a lesson (Rouadi, 2014). For students to perform different tasks, teachers can deploy cognitive scaffolds 
to expand students' ZPD through questioning, modeling, explaining, instructing, giving hints, and demonstrations, for examples. Motivational scaffolding targets engaging students and maintaining their interest in learning. Teachers should provide tasks that interest students and increase task value (Belland et al., 2013). This occurs by creating an enriching environment through group work, feedback (Miller \& Brickman, 2004), student reflection (Moos \& Azevedo, 2009), promoting positive emotions (Gross \& Thompson, 2006).

\section{Conceptual framework}

Scaffolding is useful when learners are exposed to increasingly challenging levels that require mastery to progress (Alsawaier, 2018), and receive prompts and hints that direct them towards a solution path rather than presenting the solution (Fisch, 2005, as cited by Obikwelu et al., 2012). Skill attainment involves a sequence of tasks, feedback, and a way of measuring learner achievement (Patadia, 2016). Scaffolded gamified activities help to actualize the ZPD. Figure 2 illustrates how scaffolds were gradually removed from graduated tasks in this gamification intervention in geometry involving Grade 4 elementary students. It illustrates how scaffolds initially integrated into game tasks, were gradually removed as learners progressed through challenge levels, and from full teacher and peer support to independent practice over time.

\section{Methods}

We now present design considerations and rationales for key decisions that were made in each stage of gamification intervention. We used an informed decision-making (IDM) process (Mullen et al., 2006) to gather information from key sources to apprise these decisions. These sources were the relevant research literature, our collective experiences with mathematics teacher preparation for diverse learning contexts, recommendations from the pilot study, followed by collaboration with teachers from schools selected for the intended gamification intervention.

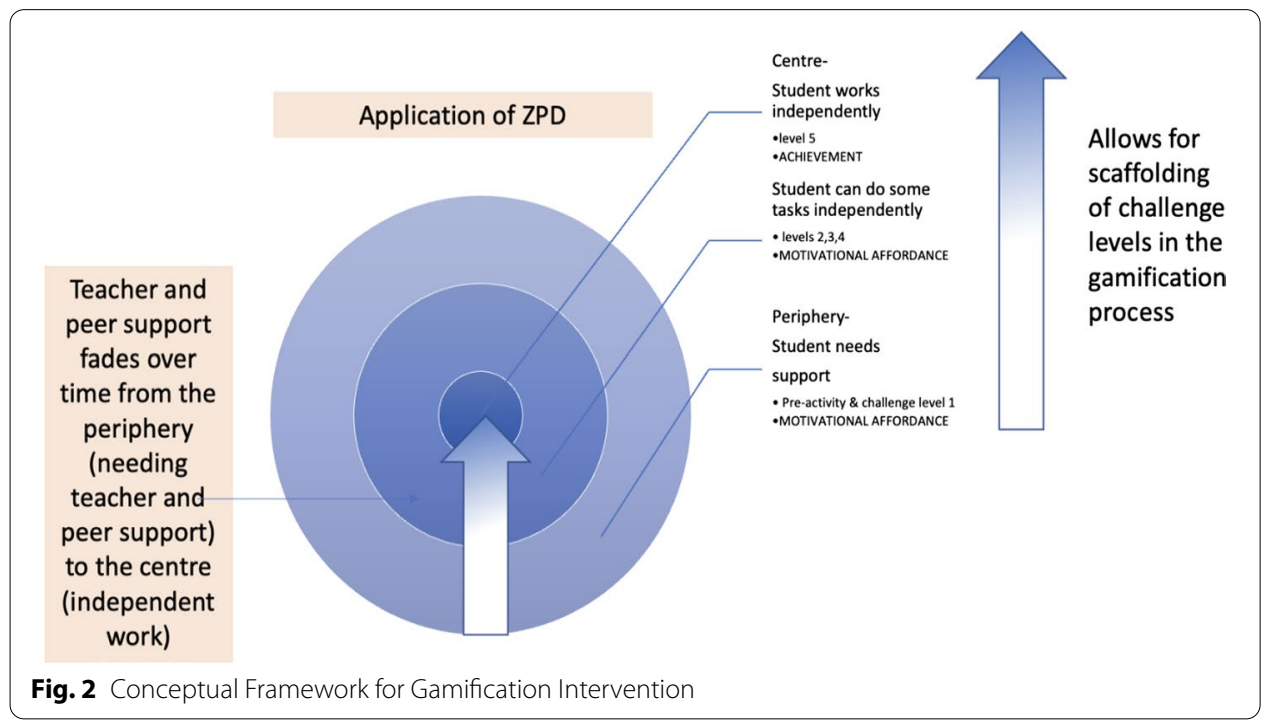


IDM is particularly well suited to education (Huffman, 1974; Schildkamp, 2012), as such, we applied the concept to the design of an instructional intervention by considering the key benefits, challenges and limitations, and the learning contexts. The research team met regularly over one year to expand on our initial understanding of gamification and arrive at a common understanding of gamification in the Trinidad and Tobago context. Our research team comprised of university teacher educators with expertise in mathematics instruction, curriculum design and development, project planning, research methods, instructional design and classroom assessment.

The pilot study was an instrumental case study involving 11-year-old students in Grade 6 at a purposefully selected private elementary school in Trinidad and Tobago. We collected and analyzed data from students and teachers in a mixed methods study. We targeted the geometry strand in the Trinidad and Tobago National Primary Mathematics Curriculum (TTNPMC, 2013) intentionally, and focused on reinforcing previously taught geometry concepts and skills through gamified Tangram and Origami puzzles, as unplugged resources. We applied the five steps in Huang and Soman's (2013) gamification model for the pilot study and used insights from findings thereof to gain new understandings for a larger study in multiple schools and diverse contexts. As gamification was new to all of us, we used multiple sources to inform the revised design which we present in this paper.

\section{Designing the gamification intervention}

In this section, we describe each step of the 5-steps of Huang and Soman's model in designing the gamification intervention and articulate how our learnings informed our decisions.

\section{STEP 1: Understanding the target audience and the context}

It is critical to completely understand the characteristics of the learners and the context of the curriculum, such as "pain points" (Huang \& Soman, 2013, p. 8) which are factors that hinder students' progress through the curriculum and achievement of its objectives. Such pain points include learners' age and level of cognitive development, learning environment, sequencing of content, among others. They assist with selecting specific gamification elements to be implemented during the planning process. The pilot study revealed the need to attend more carefully to the first level in the Huang and Soman's (2013) model when designing the games to be a meaningful learning tool, particularly with respect to closer collaboration with the class teacher who brings intimate knowledge about students and the learning environment. Consideration to the target group of students and their prerequisite knowledge and skills in the given learning context are critical to designing tasks that cover the curriculum content, and are sufficiently challenging to keep students interested in playing without frustrating them ([Authors], p. 90).

attend more carefully to the first level in the Huang and Soman's (2013) model when designing the games to be a meaningful learning tool, particularly with respect to closer collaboration with the class teacher who brings intimate knowledge about students and the learning environment. Consideration to the target group of students 
and their prerequisite knowledge and skills in the given learning context are critical to designing tasks that cover the curriculum content, and are sufficiently challenging to keep students interested in playing without frustrating them ([Authors], p. 90).

Hence, in the revised gamification design, we were more attentive to the pain points associated with learner characteristics (age and level of geometric thinking) and transforming the school environment to a more engaging one. The pilot study revealed that students responded positively to co-operative activities [Authors]. We wanted to ascertain students' pre-knowledge, the current learning environment, and opportunities for student collaboration and group work. Thus, we engaged teachers in selecting the levelappropriate curriculum content and discussed the challenges we had observed with Grade 6 students experiences in working at Level 2 of van Hiele's geometric thinking during the pilot study. We chose to focus on a younger age group-Grade 4 students -who would have attained competence at Level 1 of van Hiele's (1999) geometric thinking and would now be transitioning to developing Level 2 skills, based on the national curriculum for mathematics (TTNPMC, 2013). We continued to use unplugged resources at this earlier age, based on recommendations by Huang and Looi (2021) and Saxena et al. (2020) and selected tangrams to focus our gamification.

To increase opportunities for student success, we visited the selected schools with diverse learning contexts such as size, government-funded or not and low to high SES, to glean in-depth understandings of their school environments and gather information to inform the planning and design of the gamification intervention. The schools were not at the same level of technology readiness and thus confirmed the decision to use non-digital or unplugged resources. As such we could potentially reach more students "without the distractions of getting the resources and infrastructure for computers" (Looi et al., 2020, p. 4). Thus, we obtained the support of schools' principals, participating teachers, parents and students.

Hence, by the end of Step 1, we gleaned a good understanding of the schools' environments and physical spaces, the age and prerequisite knowledge of students to be engaged, had established working relationships with school personnel, and had decided on the curriculum content to reinforce Level 2 skills. Thus, we leveraged learnings from the pilot on context and learner characteristics which allowed us to move on to the next steps in designing the intervention as all other aspects hinged on this foundation.

\section{STEP 2: Defining learning objectives}

The gamification process must be guided by clear learning objectives (Huang \& Soman, 2013). Though the TTNPMC (2013) suggests using student-centred pedagogical approaches to improve student motivation, mathematics self-efficacy and performance in the medium to long term, specific strategies to achieve these are not specified. Games are suggested in the Number strand (see TTNPMC, 2013, p. 249) but not the geometry strand, and neither gamification nor game-based learning are mentioned in the document.

In the pilot study ([Authors]), students' responses on the pre-tests and post-tests revealed that while they recognised and classified shapes from their properties, they struggled with: (a) working with shapes when their orientation had changed, (b) applying 
Table 1 Curriculum content for geometry strand in the TTNPMC (2013)

\begin{tabular}{|c|c|}
\hline Focus & Articulation \\
\hline Content & $\begin{array}{l}\text { 2.1.4 Develop spatial sense through explorations in relation to plane shapes } \\
\text { 2.1.5 Investigate properties of plane shapes } \\
\text { 2.1.6 Solve problems involving plane shapes. (p. 181) }\end{array}$ \\
\hline Skills & 2.2.7 Explore the effects of orientation change on plane shapes (p. 185) \\
\hline Dispositions & $\begin{array}{l}\text { 2.3.2. Display collaboration while working in groups (p. 141) } \\
\text { 2.3.3. Display confidence in the exploration of plane shapes (p. 181) }\end{array}$ \\
\hline Outcomes & 3. Demonstrate an understanding of the properties of plane shapes (p. 181) \\
\hline Elaborations & $\begin{array}{l}\text { Investigate the effects of changing the orientation of a shape by first meas- } \\
\text { uring the shape and then changing its orientation and then measuring } \\
\text { again (p. 182) }\end{array}$ \\
\hline
\end{tabular}

the concept of symmetry in working with plane shapes, and (c) applying the principal of conservation of area in problem solving. This suggests that while the students were competent with concepts and skills expected at Level 1 of van Hiele's (1999) levels of thinking, they struggled with those expected at Level 2. Hence, there was a need to support students as they transition from Level 1 (analysis) to Level 2 (informal deduction). Therefore, our refined design focuses on activities that reinforce concepts and scaffold thinking for transitioning to Level 2. We gamified Tangram activities only, because they can develop concepts and skills related to shape identification and spatial relationships expected at Level 2; students in the pilot study reported greater challenges with the complexity and levels of difficulty associated with Tangrams.

Our intervention objectives included:

1. Scaffolding to reinforce geometric concepts related to plane shapes to improve spatial sense and geometric thinking.

2. Promoting manipulation of 'tans' to explore the properties and relationships of plane shapes and solve Tangram puzzles.

3. Encouraging the use of imagination to create Tangram puzzles.

4. Facilitating cooperation among peers to solve Tangram puzzles.

5. Facilitating interest, motivation, enjoyment and creativity, in applying geometric thinking.

These general objectives of the design were guided by specific curriculum objectives in the TTNPMC (2013) for Grades K-4 (called Standards 1-5). They focused on developing appropriate concepts, skills and dispositions that "would facilitate life-long learning and higher order thinking skills" (p. 22). The specific content, skills, disposition objectives and learning outcomes in geometry from the TTNPMC (2013) are listed in Table 1.

Our intervention objectives were also guided by observations of students' challenges with the content, and student and teacher reports from the pilot study which indicated that enjoyment and cooperation were motivational dimensions which enhanced engagement with the gamified activities ([Authors]).

By the end of Step 2, we had clearly identified the specific learning objectives and outcomes in geometry for the selected group of students in the main study. This allowed us to focus on structuring the learning experiences for students to achieve these stated objectives. 


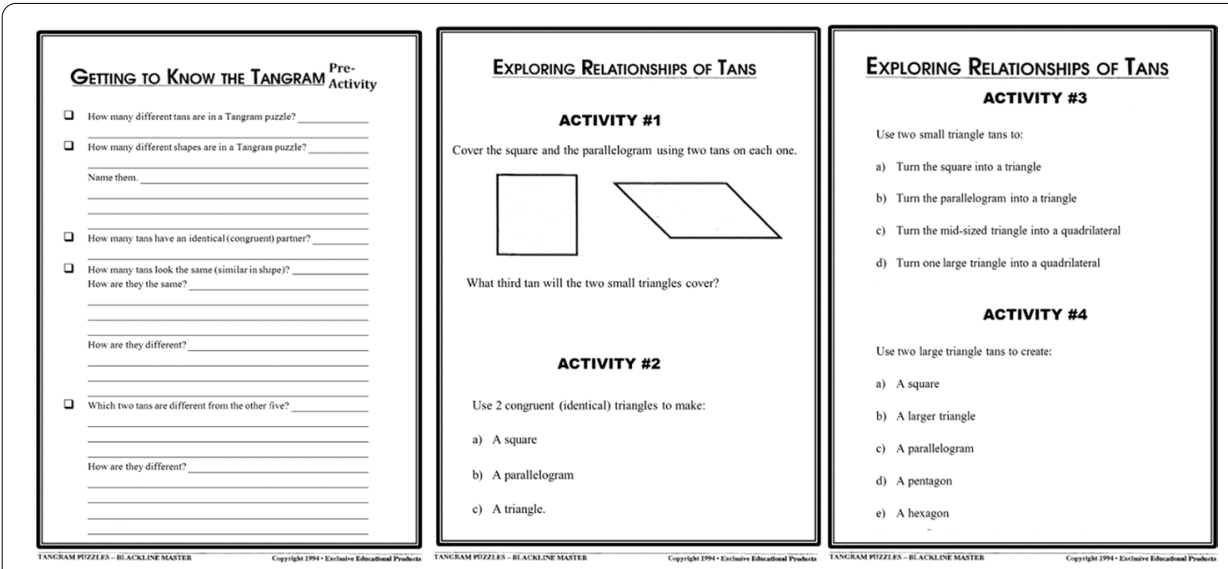

Fig. 3 Pre-activity Sheets for Stage 1 taken from Tangram Blackline Masters (1994)

\section{STEP 3: Structuring the experience}

It is important to break up educational programmes into stages, with each stage having a desirable milestone (Huang \& Soman, 2013). Stages help chunk programme objectives into manageable deliverables. Milestones help with evaluating what students have learnt and mastered and motivate students to move on to the next phase. Milestones should be easily achievable initially and then increase in demand and complexity as students' progress through the programme stages. Educators must reflect on each stage and milestone during planning for effective gamification.

In the pilot study, students reported that some of the tangram activities were too complex and challenging, some shapes were difficult to construct, and they needed more instructions that were easier to understand ([Author]). To address these observations, we chunked the learning material into graduated stages in the new design, which we referred to as challenge levels. This approach would scaffold students' transition from Level 1 to Level 2 of van Hiele's (1999) geometric thinking. We noted that we had not oriented these students to the set of tans comprising the tangram or allowed play with the tans ahead of using them for learning tasks. This may have contributed to the challenges students reported about completing Tangram puzzles. Hence, we developed six stages that started with a pre-activity followed by five challenge levels that increased in difficulty and complexity. Every stage was designed with increasing complexity to scaffold students' transition through the levels of thinking. Each level targeted specific objectives aligned to those in the TTNPMC (2013). Tangram manipulation allowed teachers to use visualization and manipulation for exploring practical problems on all the five challenge levels, to reinforce the properties of plane shapes and their relationships with each other for developing deductive reasoning (Siew et al., 2013). Tangram activities were sourced from Tangram Blackline Masters (1994) which gives free reproduction rights to educators (p. ii).

\section{Stage 1: Pre-activity}

The pre-activity was a non-competitive level that introduced students to the Tangram (see Fig. 3). Students would investigate the properties of the Tangram pieces and make decisions about how to manipulate specific pairs of tans to cover the surface area of 
Using Fewer than Seven Tans to Solve Puzzles Level 1

口 Use $\Delta \Delta \triangle$ and $\square$ to fill each space below.

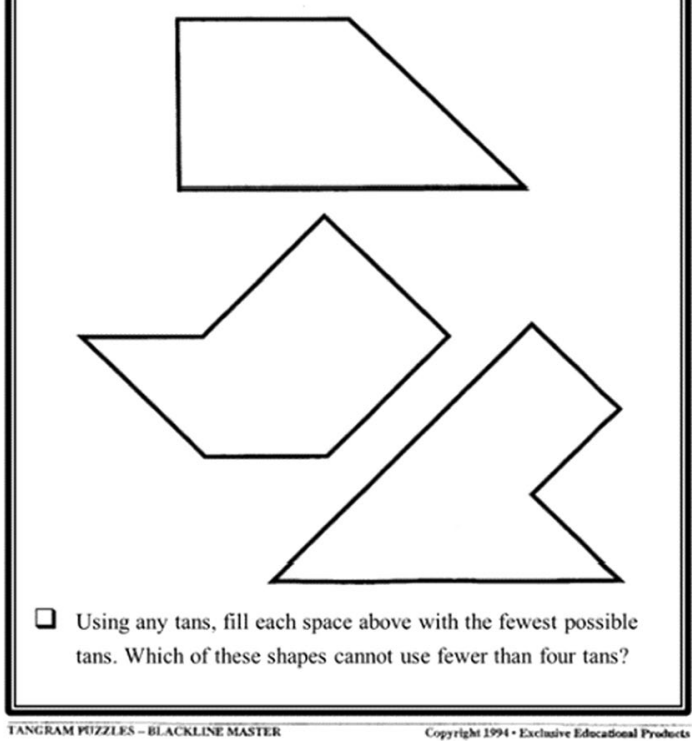

Fig. 4 Challenge Level 1 Sheet for Stage 2 taken from Tangram Blackline Masters (1994)

different shapes and form compound shapes without overlapping tans. These activities were scaffolded, offering students explicit instructions about which tans to use to complete the activities. They would use a pencil to trace the perimeter of the tans to preserve their shapes once the tans were removed; this instruction would hold for all subsequent levels. This pre-activity was critical to establishing the foundation for the challenge levels that followed and reinforced the TTNPMC (2013) content objectives 2.1.4, 2.1.5, 2.1.6, skill 2.2.7, disposition 2.3.2, and learning outcome 3. The milestone at this stage was students' ability to successfully manipulate pairs of tans to create shapes.

\section{Stage 2: Challenge level 1}

Students would initially manipulate four specific tans to cover the surface of given compound shapes, and then identify any other combination of tans that would cover the same shape (see Fig. 4). This activity provided students with explicit instructions about which tans to use to cover the shape. It would probe their understanding of the properties of and relationships among these tans and decisions they made about manipulating them. It also reinforces the principle of conservation of area by allowing them to cover the surface area of a compound shape with different combinations of plane shapes in different orientations. In the pilot study, students reported difficulty with creating Tangram puzzles using all seven tans ([Authors]), which suggests that students needed to first manipulate fewer tans and progress to more complex Tangram puzzles with more tans. This level attended to reinforcing TTNPMC (2013) content objectives 2.1.4, 2.1.5, and 2.1.6, skills 2.2.7 and disposition objectives 2.3 .2 and learning outcome 3 . The milestone 


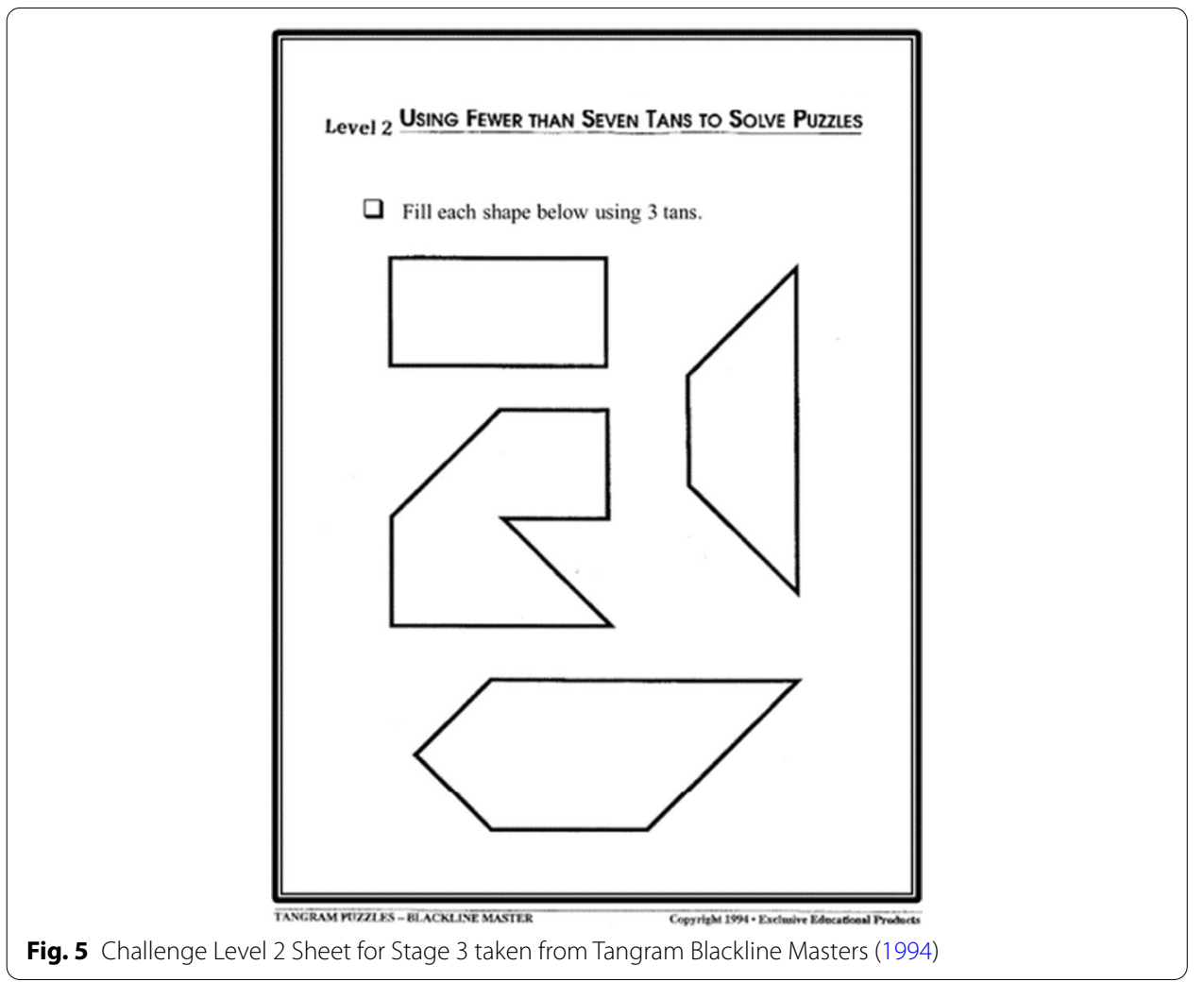

in this level is that students would move from manipulating two tans to four tans to cover a compound shape.

\section{Stage 3: Challenge level 2}

Students would select and manipulate any three tans to cover the surface area of compound shapes (see Fig. 5). The activity further probed their deductive reasoning and decision-making skills while manipulating tans. Lifting the restriction of using specific tans removes scaffolds (specific instructions) and gradually increases the cognitive demand on students. This will allow them more flexibility in problem solving and reinforce the same TTNPMC (2013) content as Challenge Level 1. The milestone in this level is that students can successfully complete the challenge using any three tans to cover compound shapes.

\section{Stage 4: Challenge level 3}

Students would manipulate combinations of three, four or five tans to cover a given compound shape (see Fig. 6). This activity increased the number of tans to be used from three to five. We increased the cognitive demand by removing more scaffolds and allowing students to be creative in their decision making as they progressively used more tans in solving Tangram puzzles. This level reinforced the same TTNPMC (2013) content as Challenge Level 2 and introduced disposition objective 2.3.3 relating to confidence in exploring plane shapes. The milestone in this challenge is that students could use informal deduction to make decisions about covering a more complex compound shape than 
Using Fewer than Seven Tans to Solve Puzzles level 3

How may ways can you fill this space?

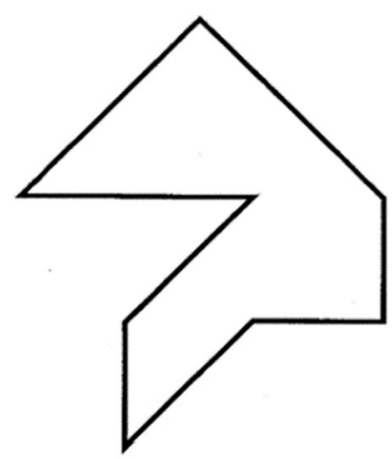

There are at least 3 ways to cover this space.

One using:

- 3 tans

- 4 tans

- 5 tans

Can you find more solutions?

Fig. 6 Challenge Level 3 Sheet for Stage 4 taken from Tangram Blackline Masters (1994)

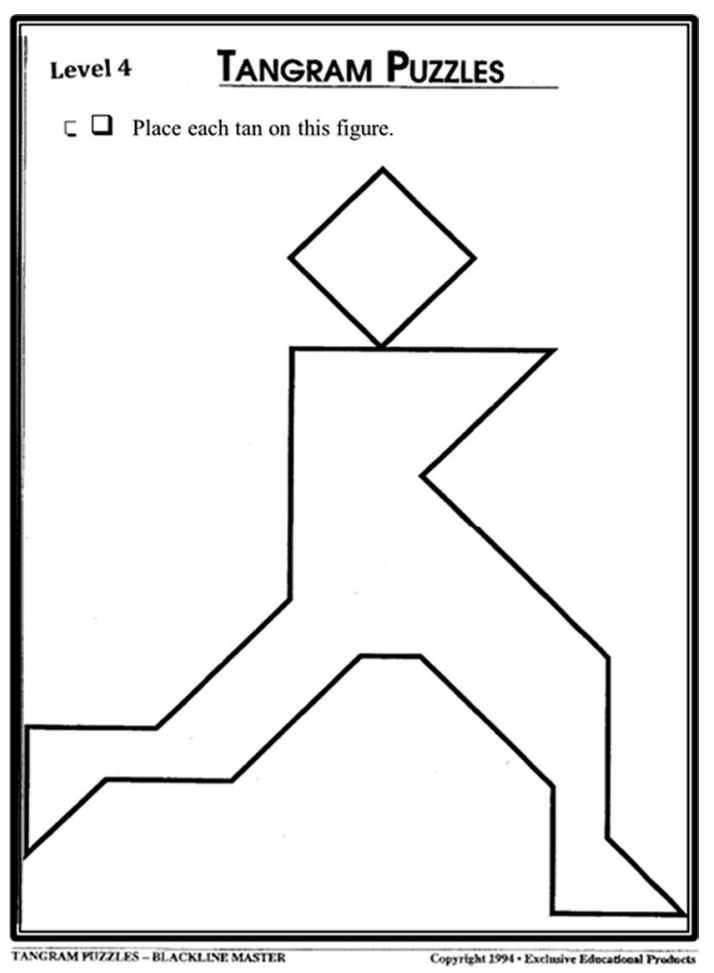

Fig. 7 Challenge Level 4 Sheets for Stage 5 taken from Tangram Blackline Masters (1994) 


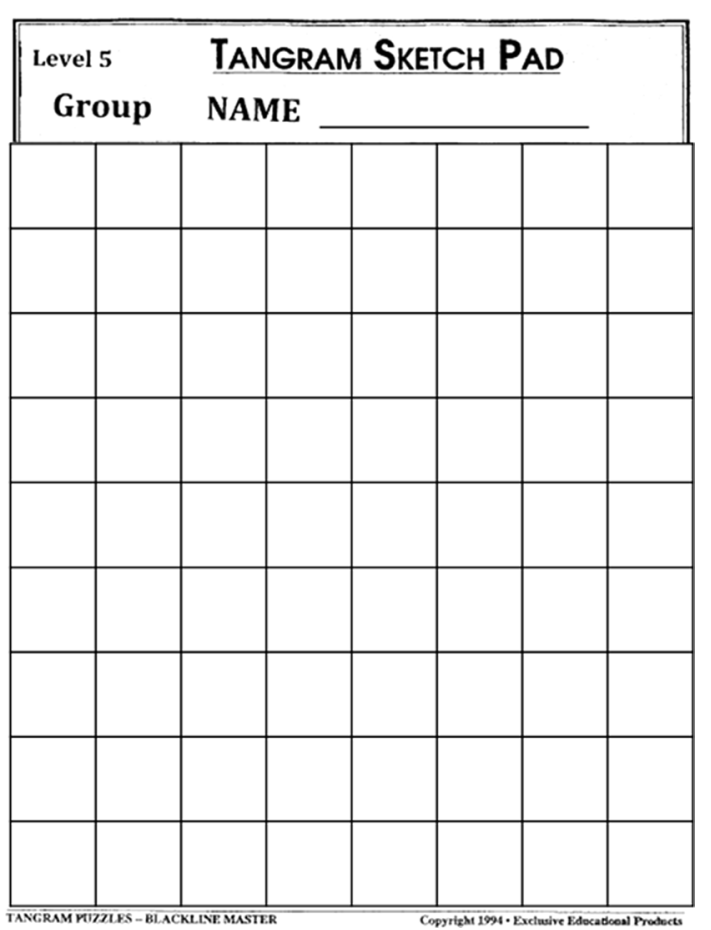

Fig. 8 Challenge Level 5 Sheet for Stage 6 taken from Tangram Blackline Masters (1994)

in previous levels, with no restriction on which tans could be used, only on the number of tans.

\section{Stage 5: Challenge level 4}

Students would be required to use all seven tans to cover the surface of a well-known Tangram puzzle (see Fig. 7). We designed this challenge to allow students to demonstrate their understanding of the properties of plane shapes, their relationship to each other, and use their developing spatial sense and geometric thinking to manipulate tans to cover the shape. This level reinforced the same TTNPMC (2013) content as Challenge Level 3. The milestone in this challenge is that students would rely on deductive reasoning to complete the task without any scaffolds that were previously provided.

\section{Stage 6: Challenge level 5}

Students would use all seven tans to create their own Tangram puzzle for their peers to solve (see Fig. 8). We decided to provide students with the opportunity to be creative in designing and naming a Tangram puzzle. We thought this approach would contribute to students' enjoyment if they could see their creations on display and challenge other students to complete a puzzle that they created themselves. This level reinforced the same TTNPMC (2013) content as Challenge Level 4. The milestone here is that students would demonstrate their understanding of the properties of the tans to design a unique shape. 


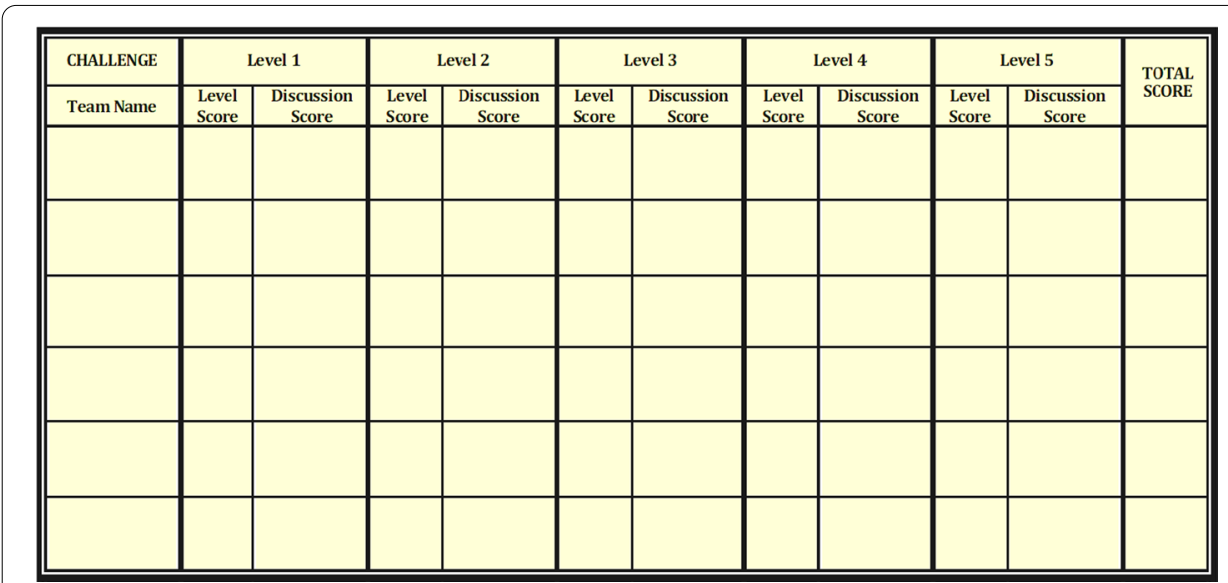

Fig. 9 Leader Board Designed for the Gamification Intervention

By the end of Step 3, informed by learnings from the pilot we included a pre-activity to orient students, and chunked the curriculum content into smaller tasks to provide students with the experience of gradually moving from working fewer tans to a full set of seven tans. They would move from simple to more complex Tangram puzzles as scaffolds are removed. This step allowed us to identify the resources required for each Challenge Level.

\section{STEP 4: Identifying resources}

Identifying resources is a critical stage in the gamification process for successful implementation (Huang \& Soman, 2013). First, we developed the implementation procedure for teachers, which is elaborated below. We then sourced and produced the required resources for the gamification design in the five schools. This approach is an important step following the pilot study that involved only one school. It facilitates standardisation and coordination of processes across the schools and minimises possible variations in implementation procedures that may contribute to differences between expected and observed outcome (McBryde et al., 2004).

\section{Resources for the gamification}

We produced a resource kit with seven items. Each of the five participating schools would receive one kit per classroom. Kits comprised:

1. One Tangram set (7 pieces) per student made from Bristol board and stored in small Ziploc bags

2. A leader board made from Bristol board to record groups' scores as they progress through the Challenge Levels (see Fig. 9)

3. A discussion board made from Bristol board and $3 \mathrm{~cm} \mathrm{x} 3 \mathrm{~cm}$ Post-it notes to record hints for other groups that need assistance (see Fig. 10)

4. Colour-coded folders for each stage in Step 3 that contained: 


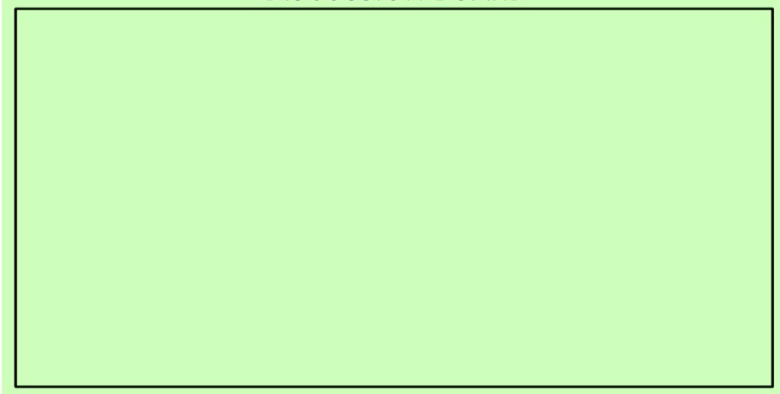

Fig. 10 Sample Discussion Board

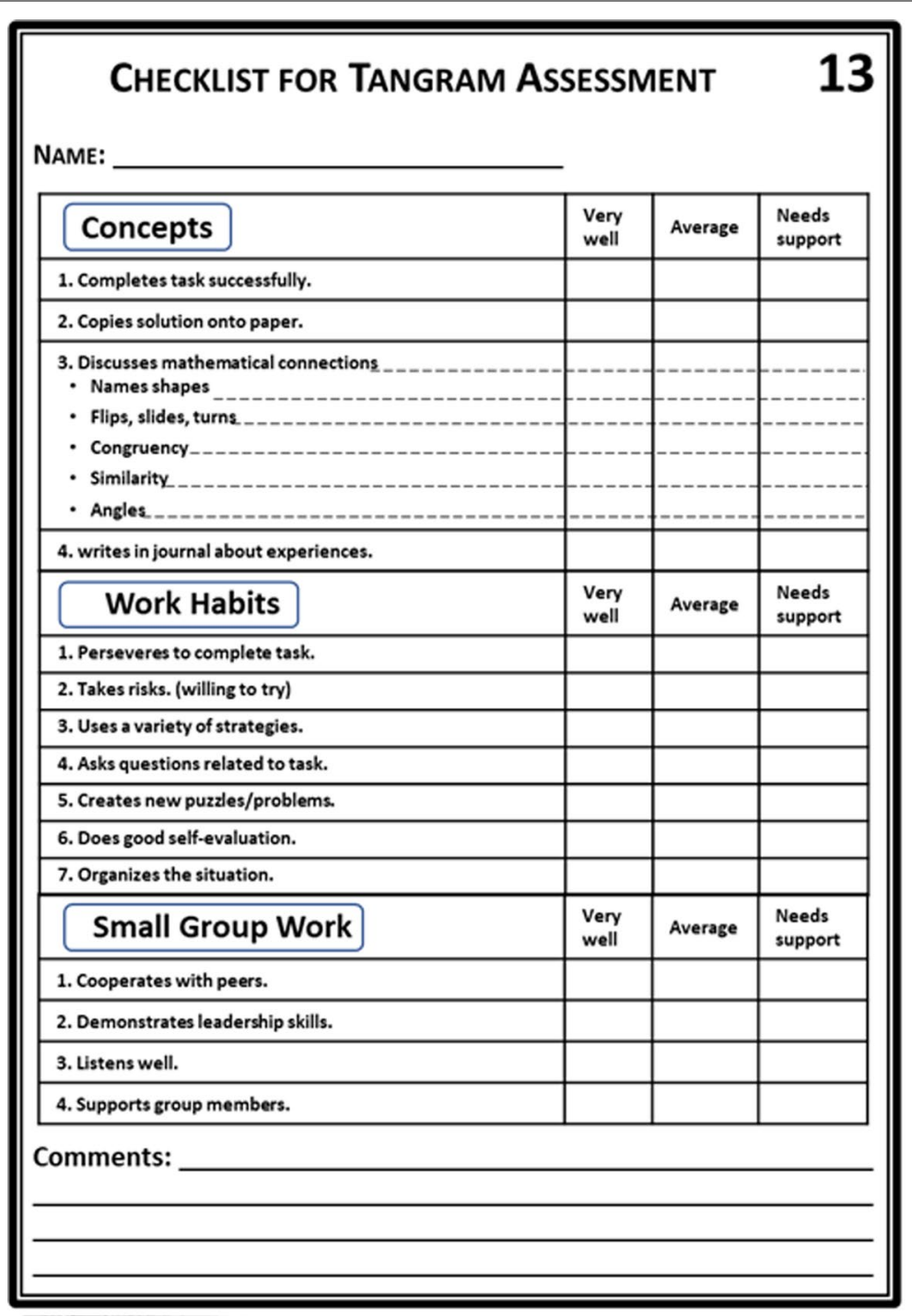

TANGRAM PIZZLES - BLACKLLNE MLSTER

Copyright 1994 - Excluuive Edocatiosal Protocts

Fig. 11 Teacher Checklist taken from Tangram Blackline Masters (1994) 


\section{Self Evaluation Comments: Tangram NAME: PROBLEM\#}

$\square_{\text {I found the problem(s): }}$ easy average difficult

$\square_{\text {I found more than one solution: }}$ yes no

$\square$ I sketched my solution(s) on paper: yes no

The main strategy I used to work on the problem was

$\square$ Math ideas in this problem included

This problem reminded me of another one.

$\square$ I know I'm improving because

$\square \mathrm{I}$ do (or) do not (circle one) enjoy these problems because

To work better in a group, I would

$\square$ Questions I have:

Fig. 12 Student Reflection Sheets taken from Tangram Blackline Masters (1994)

a. Individual activity tan sheets (colour-coded to match folders) for students to work with in group challenges.

b. Teacher checklist for group challenge activity to allow the teacher to monitor and track student engagement and participation in group activities (see Fig. 11).

c. Student self-evaluation sheet per challenge level to allow students to reflect on their learning and progress as they moved through each Challenge Level (see Fig. 12).

5. Pencils, markers, glue, tape, sheets of glitter stars.

6. Implementation procedure to guide the teachers implementing the gamification design.

7. Envelopes containing the pre-tests and post-tests for teachers to administer to students. 
Table 2 Scoring chart for the challenge levels

\begin{tabular}{llllll}
\hline Challenge level & 1 & 2 & 3 & 4 & 5 \\
Maximum score & 2 & 4 & 6 & 8 & 10 \\
\hline
\end{tabular}

Table 3 Discussion Board Rubric

\begin{tabular}{llll}
\hline Post & Score $\mathbf{5}$ & Score $\mathbf{3}$ & Score $\mathbf{0}$ \\
\hline Hint & $\begin{array}{l}\text { Suggests viable alternative strategies to } \\
\text { solving the puzzle }\end{array}$ & Suggests routine strategies to puzzle solving & No post \\
Comment & Provides valuable assistance to others & Provides vague assistance to others & No post \\
Question & Asks insightful questions & Asks a predictable question & No post \\
\hline
\end{tabular}

The implementation procedure is detailed hereunder.

1. The teacher administers the pre-test to all students.

2. The teacher organises students into groups of three or four and distributes to each group member, a set of tans, challenge sheets, and self-evaluation sheets. Groups receive Post It notes, pencils, markers, and glue.

3. The teacher places the leader board and discussion board on a wall for all students to access freely and to provide transparency to the process. The teacher records groups' names on the leader board.

4. The teacher introduces students to a gamified vocabulary (e.g., hints, leader board, badges, challenge, and stars) and discusses gamification instructions with students.

5. The teacher guides students through the pre-activity.

6. The teacher begins the competition, monitors groups and records their scores on the leader board.

7. A challenge level is completed when the teacher verifies the solution through visual inspection of students' work. Each Challenge Level earns a maximum score upon completion (see Table 2). The overall maximum possible score is 30 . Penalties are not applied to limit interfering with student motivation.

8. When a group completes a challenge, members can post a hint, comment, or guiding question on the discussion board to assist other groups. Groups' contributions are assessed by the teacher using a rubric (see Table 3) and recorded on the leader board. Points are awarded based on the quality of the contribution and ranged from 0 (low quality) to 5 (high quality). A group's total score is the sum of these points plus points from Challenge Levels.

9. At the end of each Challenge Level the teacher completes the checklist and students fill in the self-evaluation sheets.

10. The game ends when all groups have completed all challenge levels. Teams are awarded stars based on the order of correct completion of each challenge level. The teacher totals the scores and announces the winning group.

11. The teacher administers the post-test. 
By the end of Step 4, we had identified, sourced and created the resources for each stage and Challenge Level described in Step 3, including detailed guidelines and instructions for teachers, resources for students and for documenting students' participation and progress. We built on and refined the wording of the guidelines, instructions and resources used in the pilot study, based on observations of improvements needed. This step would minimise discrepancies in subsequent gamification implementation across schools. It also allowed us to apply appropriate gamification elements in the next step.

\section{STEP 5: Applying gamification elements}

Huang and Soman (2013) suggest that it is the education program that guides the decisions and refinement of gamification elements. It is important that two classes of elements, self-elements, and social elements, are addressed. Cognitive and motivational scaffolding can promote self-elements and social elements in gamification challenges. Huang and Soman gave examples of self-elements as "points, achievement badges, levels, or simply time restrictions" (p. 13). This type of gamification element places emphasis on individual progress and self-achievement. Self-elements are closely related to the social elements. Social elements relate to how groups compete, interact, and cooperate within the community. An example of this type of gamification element is the use of leader boards. This tool assists with charting and publicizing groups' progress and achievement. Both self and social elements have a unique purpose; hence, it is important for the success of the gamified activities to carefully plan when each type of element is used. Self-elements are used for more challenging tasks, so as not to demotivate students, but rather amplify students' personal achievement. The social elements are used to motivate students as a group or community to move on together, to the next or higher levels. Consequently, our design incorporated both types of gamification elements.

Our learning from the pilot study highlighted how social elements enabled a sense of cooperation through social interaction within the competitive environment of a gamified classroom ([Authors]). Cooperation and competition are aspects of gamification that facilitate students working together towards goal achievement which embraces "the winning state of cooperative gamification" (Kapp, 2014, para.2). Thus, in designing this study, we decided to amplify social elements through cooperation by including opportunities for meaningful dialogue and student interaction within and among teams. Within teams, students can assist each other through scaffolded activities to complete Challenge Levels successfully (Obikwelu et al., 2012). Collaborative student interactions can produce gains in knowledge, practical, and social skills as students engage in the learning process (Parga, 2011). The social elements are emphasized by displaying team points on the leader board after successive Challenge Levels, and through the discussion board where hints can be placed to assist other teams. In Step 1 of the gamification process, we collaborated with teachers to facilitate creating supportive learning environments in their respective schools. They would monitor teams' progress using the observation checklist provided to ensure they complete each level before progressing to the next.

We attended to the self-elements by planning Challenge Levels that were graded by difficulty and scaffolded through peer collaboration, and using points, rewards, ranks 
and levels for motivation and engagement (Pesare et al., 2016) creating a sense of accomplishment. Through the years there has been continuous debate whether extrinsic rewards lower intrinsic motivation (Alsawaier, 2018; Deci et al., 2001), but gamification designers can mitigate this risk by including motivational scaffolding for student emotions. The self-element can be developed by identifying challenges, providing opportunities for improvement, celebrating successful outcomes, and peer support in solving given tasks. Self-evaluation is a key component for social constructivism and motivation (Shepard, 2001). Students can use self-evaluation to positively influence the self-element. Self-evaluation aims to develop learners' skills, competencies, and responsibility for their own learning. Students can identify gaps in their knowledge, and skills that require more practice. In our gamification design, we planned to provide the students with tools for self-monitoring by including self-evaluation sheets.

This gamification design is supported by Hamari et al. (2016) who suggest that offering activities that are within the learners' ZPD, challenges them within an appropriate skill level, thus maximizing engagement. In this design, the focus is on peers collaborating at different levels of difficulties, rather than the teacher aiding individual students, through skilful cognitive scaffolding to execute the learning task more effectively. Thus, by the end of this step, we drew on the findings of the pilot study that supported teamwork and collaboration, which was also a desired disposition of the TTNPMC (2013).

\section{Conclusions and recommendations}

This paper presents our insights on designing a gamification intervention for enhancing the mathematics learning environment for elementary students to attain mastering of geometry. Thus, our gamification design seeks to transform the dull learning environment to a smart one, by engaging learners actively (Pesare et al., 2016). We incorporated cognitive and motivational scaffolding strategies to build students' confidence in geometry, through collaborative interactions that facilitate student satisfaction and enjoyment (Baldeón et al., 2015) as they work towards goal achievement. The increasing complexity of challenge levels used a fading technique from team collaboration to independent practice to support students' success (Obikwelu et al., 2012). Designing the intervention required using our insights from a pilot study, and flexible thinking to implement gamification, an emerging pedagogical approach, using Huang and Soman's (2013) gamification model in our educational context.

This paper bridges theory and practice on gamification by providing insights into how social constructivism, specifically Vygotsky's (1978) ZPD and van Hiele's levels of geometric thinking support the design of an intervention. Our gamification design clearly targeted national mathematics curriculum objectives even though gamification is not specified as a learning strategy in the geometry strand of the TTNPMC (2013). Hence, curriculum developers should intentionally include gamification as a strategy in geometry and other strands in the curriculum.

This paper highlights the use of unplugged activities so that teachers across any school context can use gamification to improve cognitive and motivational engagement in learning geometry. We considered the scalability of the intervention and used an unplugged geometrical resource- the tangram-to broaden access to a wide range of learners (Huang \& Looi, 2021), and of a young age (Saxena et al., 2020). Teachers should 
not be afraid to enhance learning environments with gamification (Erenli, 2013) and this paper illustrates one approach which teachers can leverage. The accessibility of our design can assist even a reluctant teacher to gamify learning environments. It takes time and effort to design these activities and many teachers may feel burdened to do this on their own (Looi et al, 2020). Our work can reduce the disconnect between classroom instruction and educational research to improve teaching and learning (Clements et al., 1997), while paying attention to learner characteristics (Smiderle et al., 2020).

In moving forward, we invite educators across diverse learning contexts to implement this intervention to contribute rich and varied experiences to further enhance the design. We recommend that educators be open minded about embracing gamification that can bring joy and learning. Gamification is not interchangeable with play or even games, though both have utility in children's learning. We have learnt that designing a gamification intervention requires a great deal of time in planning and game elements need to be incorporated purposefully. Balancing internal and external motivation factors for young children remain an area for future research and gamification continues to hold the attention of educational researchers who seek better models for enhanced learning environments.

\footnotetext{
Abbreviations

TTNPMC: Trinidad and Tobago National Primary Mathematics Curriculum; SEA: Secondary Entrance Assessment examination; ZPD: Zone of proximal development; IDM: Informed decision making.
}

\section{Acknowledgements}

The authors acknowledge the University School at St. Augustine, Trinidad as the site of the pilot study and thank the administration and teachers of the pilot and schools of the main study for their cooperation and support.

\section{Authors' contributions}

VJK was the leader of the research project and led the writing team. NR-J and SJ made substantial contributions to the Huang and Soman's model. SF-H and ZD established the theoretical foundations of the study and searched and analyzed the literature. All authors drafted this manuscript, improved the manuscript's language and flow, and commented on the manuscripts with numerous edits. The author(s) read and approved the final manuscript.

\section{Funding}

The University of the West Indies at St. Augustine, Trinidad and Tobago support this research work through a research grant CRP 10. The funding helped to provide software and to offset material production cost for the teacher gamification toolkits

\section{Availability of data and materials}

The data from the pilot study can be made available upon request and the published article from that study can be added to the reference list but is currently removed for peer review. Materials used in this study are supplied as figures.

\section{Declarations}

Competing interests

The authors have no conflicts of interest to disclose and permit any reviewer to review our manuscript.

\section{Author details}

${ }^{1}$ School of Education, The University of the West Indies, Gordon Street, St. Augustine, Trinidad and Tobago. ${ }^{2}$ Texas Technology University, Lubbock, Texas, USA.

Received: 24 July 2021 Accepted: 7 December 2021

Published online: 17 December 2021

\section{References}

Alsawaier, R. S. (2018). The effect of gamification on motivation and engagement. The International Journal of Information and Learning Technology, 35(1), 56-79.

Aridi, S. N., \& Saad, M. M. (2020) Gamification for elementary geometry learning: Is it a recommended scenario? In Proceeding of first conference Alexandria pedagogical innovation and technology enhance, APITEL, Egypt. 
Belland, B., Kim, C., \& Hannafin, M. (2013). A framework for designing scaffolds that improve motivation and cognition. Educational Psychologist, 48(4), 243-270.

Baldeón, J., Puig, A., Rodríguez, I., Lopez, M., Grau, S., \& Escayola, M. (2015). Gamification of elementary math learning: A game designer role-playing experience with kids. Workshop on Gamification in Education: Barcelona, Spain.

Boggan, M., Harper, S., \& Whitmire, A. (2010). Using manipulatives to teach elementary mathematics. Journal of Instructional Pedagogies, 3, 1-6.

Clements, D. H., Battista, M. T., Sarama, J., \& Swaminathan, S. (1997). Development of students's spatial thinking in a unit on geometric motions and area. The Elementary School Journal, 98(2), 171-186.

Clements, D. H. (2004). Geometric and spatial thinking in early childhood education. In D. H. Clements, J. Sarama, \& A. M. Dibiase (Eds.), Engaging young children in mathematics: Standards for early childhood mathematics education (pp. 7-72). Erlbaum.

Cobb, P., Yackel, E., \& McClain, K. (Eds.). (2012). Symbolizing and communicating in mathematics classrooms: Perspectives on discourse, tools, and instructional design. Routledge.

Dabbagh, N. (2003). Scaffolding: An important teacher competency in online learning. TechTrends, 47(2), 39-44.

D'Angour, A. (2013). Plato and play: Taking education seriously in ancient Greece. American Journal of Play, 5(3), 293-307.

Deci, E. L., \& Ryan, R. M. (2000). The" what" and" why" of goal pursuits: Human needs and the self-determination of behavior. Psychological Inquiry, 11(4), 227-268.

Deci, E. L., Koestner, R., \& Ryan, R. M. (2001). Extrinsic rewards and intrinsic motivation in education: Reconsidered once again. Review of Educational Research, 71(1), 1-27.

Deterding, S., Dixon, D., Khaled, R., \& Nacke, L. (2011). From game design elements to gamefulness: Defining "gamification". In Proceedings of the 15th international academic MindTrek conference: Envisioning future media environments (pp. 9-15).

Deterding, S. (2012). Gamification: Designing for motivation. Interactions, 19(4), 14-17.

Dichev, C., \& Dicheva, D. (2017). Gamifying education: What is known, what is believed and what remains uncertain: A critical review. International Journal of Educational Technology in Higher Education, 14(9), 1-36. https://doi.org/ 10.1186/s41239-017-0042-5

Dichev, C., Dicheva, D., \& Irwin, K. (2020). Gamifying learning for learners. International Journal of Educational Technology in Higher Education, 17(1), 1-14. https://doi.org/10.1186/s41239-020-00231-0

Duru, A. (2010). The experimental teaching in some topics of geometry. Educational Research and Reviews, 5(10), 584-592.

Erenli, K. (2013). The Impact of gamification-recommending scenarios. International Journal of Emerging Technologies in Learning, 8(2013), 15-21.

Faghihi, U., Brautigam, A., Jorgenson, K., Martin, D., Brown, A., Measures, E., \& Maldonado-Bouchard, S. (2014). How gamification applies for educational purpose specially with college algebra. Procedia Computer Science, 41 , 182-187. https://doi.org/10.1016/j.procs.2014.11.102

Fisch, S. M. (2005). Making educational computer games "educational". In Proceedings of the 2005 conference on Interaction design and children (pp. 56-61)

Fuys, D., Geddes, D., \& Tischler, R. (1988). The van Hiele model of thinking in geometry among adolescents. Journal for Research in Mathematics Education Monograph, 3, i-196.

Gross, J. J., \& Thompson, R. A. (2006). Emotion regulation: Conceptual foundations. In J. J. Gross (Ed.), Handbook of emotion regulation (pp. 3-24). The Guildford Press.

Hamari, J., Shernoff, D. J., Rowe, E., Coller, B., Asbell-Clarke, J., \& Edwards, T. (2016). Challenging games help students learn: An empirical study on engagement, flow and immersion in game-based learning. Computers in Human Behavior, 54, 170-179.

Hannafin, M., Land, S., \& Oliver, K. (1999). Open learning environments: Foundations, methods, and models. Instructional-Design Theories and Models: A New Paradigm of Instructional Theory, 2, 115-140.

Hodara, M. (2011). Improving pedagogy in the developmental mathematics classroom. CCRC Brief, 51, 1-4.

Huang, W., \& Looi, C. K. (2021). A critical review of literature on "unplugged" pedagogies in K-12 computer science and computational thinking education. Computer Science Education, 31(1), 83-111. https://doi.org/10.1145/ 3408877.3432400

Huang, W. H. Y., \& Soman, D. (2013). Gamification of education. Research report series: Behavioural economics in action, 29. Rothman School of Management, University of Toronto.

Huffman, W. (1974). Decision making: The role of education. American Journal of Agricultural Economics, 56(1), 85-97. https://doi.org/10.2307/1239349

Hung, A., Zarco, E., Yang, M., Dembicki, D., \& Kase, M. (2017). Gamification in the wild: Faculty perspectives on gamifying learning in higher education. Issues and Trends in Educational Technology, 5(2), 4-22. https://doi.org/10.2458/ azu_itet_v5i2_hung

Juul, J. (2005). Half-real. Video games between real rules and fictional worlds. The MIT Press.

Jones, K. (2002). Issues in the teaching and learning of geometry. In L. Haggarty (Ed.), Aspects of teaching secondary mathematics: Perspectives on practice (pp. 121-139). Routledge Falmer.

Kapp, K. M. (2012). Games, gamification, and the quest for learner engagement. Training and Development, 66(6), $64-68$.

Kapp, K. M. (2014). Competition and cooperation in Gamification. http://karlkapp.com/competition-cooperation-ingamification/.

Kimble, T. (2020). The impact of gamification on the mathematics achievement of elementary students. (Publication No 43) [Doctoral dissertation, Kennesaw State University] DigitalCommons@Kennesaw State University. https://digit alcommons.kennesaw.edu/teachleaddoc_etd/43.

Lämsä, J., Hämäläinen, R., Aro, M., Koskimaa, R., \& Äyrämö, S. M. (2018). Games for enhancing basic reading and maths skills: A systematic review of educational game design in supporting learning by people with learning disabilities. British Journal of Educational Technology, 49(4), 596-607. 
Landers, R. N., \& Callan, R. C. (2011). Casual social games as serious games: The psychology of gamification in undergraduate education and employee training. In M. Ma, A. Oikonomou, \& L. C. Jain (Eds.), Serious games and edutainment applications (pp. 399-424). Springer.

Looi, C. K., Wu, L., Seow, P. S. K., \& Huang, W. (2020). Researching and developing pedagogies using unplugged and computational thinking approaches for teaching computing in the schools. Office of Education Research, National Institute of Education.

McBryde, C., Ziviani, J., \& Cuskelly, M. (2004). School readiness and factors that influence decision making. Occupational Therapy International, 11, 193-208.

Miller, R. B., \& Brickman, S. J. (2004). A model of future-oriented motivation and self-regulation. Educational Psychology Review, 16(1), 9-33.

Moos, D. C., \& Azevedo, R. (2009). Learning with computer-based learning environments: A literature review of computer self-efficacy. Review of Educational Research, 79, 576-600.

Moyer, P. S. (2001). Are we having fun yet? How teachers use manipulatives to teach mathematics. Educational Studies in Mathematics, 47(2), 175-197.

Mullen, P. D., Allen, J. D., Glanz, K., Fernandez, M. E., Bowen, D. J., Pruitt, S. L., Glenn, B. A., \& Pignone, M. (2006). Measures used in studies of informed decision making about cancer screening: A systematic review. Annals of Behavioral Medicine, 32(3), 188-201.

Nand, K., Baghaei, N., Casey, J., Barmada, B., Mehdipour, F., \& Liang, H. N. (2019). Engaging children with educational content via Gamification. Smart Learning Environments, 6(1), 1-15. https://doi.org/10.1186/s40561-019-0085-2

Obikwelu, C., Read, J., \& Sim, G. (2012). The scaffolding mechanism in serious games. Fun and Game, 9, 4-6.

Ojose, B., \& Sexton, L. (2009). The effect of manipulative materials on mathematics achievement of first-grade students. Mathematics Education, 12, 3-14.

Parga, F. (2011). Cooperative structures of interaction in a public school EFL classroom in Bogotá. Colombian Applied Linguistics Journal, 13(1), 24-38.

Patadia, H. J. (2016). A strategy for mastery learning in fifth grade geometry. [Doctoral dissertation, The Maharaja Sayajirao University of Baroda]. http://hdl.handle.net/10603/59594

Pesare, E., Roselli, T., Corriero, N., \& Rossano, V. (2016). Game-based learning and gamification to promote engagement and motivation in medical learning contexts. Smart Learning Environments, 3(1), 1-21. https://doi.org/10 1186/s40561-016-0028-0

Plass, J. L., Homer, B. D., \& Kinzer, C. K. (2015). Foundations of Game-Based Learning. Educational Psychologist, 50(4), 258-283. https://doi.org/10.1080/00461520.2015.1122533

Republic of Trinidad and Tobago Ministry of Education [TTNPMC] (2013). The Primary School Curriculum- Mathematics Infant 1 to Standard 5. https://www.moe.gov.tt/curriculum-guides/.

Rincon-Flores, E. G., Gallardo, K., \& de la Fuente, J. M. (2018). Strengthening an educational innovation strategy: Processes to improve gamification in calculus course through performance assessment and meta-evaluation. International Electronic Journal of Mathematics Education, 13(1), 1-11.

Rouadi, N. (2014). A new reading to scaffolding in geometry. International Journal of Arts and Commerce, 3(5), $127-141$.

Russell, D., \& Bologna, E. (1982). Teaching geometry with tangrams. The Arithmetic Teacher, 30(2), 34-38.

Salen, K., \& Zimmerman, E. (2004). Rules of play. The MIT Press.

Salifu, A. S., Yakubu, A. R., \& Ibrahim, F. I. (2018). van Hiele geometric thinking levels of pre-service teachers of EP college of education, Bimbilla-Ghana. Journal of Education and Practice, 9(23), 108-119.

Sarama, J., \& Clements, D. H. (2009). "Concrete" computer manipulatives in mathematics education. Child Development Perspectives, 3(3), 145-150.

Schildkamp, K., Lai, M. K., \& Earl, L. (Eds.). (2012). Data-based decision making in education: Challenges and opportunities, (Vol. 17). Springer Science \& Business Media.

Saxena, A., Lo, C. K., Hew, K. F., \& Wong, G. K. W. (2020). Designing unplugged and plugged activities to cultivate computational thinking: An exploratory study in early childhood education. The Asia-Pacific Education Researcher, 29(1), 55-66. https://doi.org/10.1007/s40299-019-00478-w

Shepard, L. A. (2001). The role of classroom assessment in teaching and learning. (CSE Technical Report 517). The Regents of the University of California. https://nepc.colorado.edu/sites/default/files/publications/TECH517.pdf.

Siew, N. M., Chong, C. L., \& Abdullah, M. R. (2013). Facilitating students' geometric thinking through van Hiele's phased-based learning using tangrams. Journal of Social Sciences, 9(3), 101-111.

Smiderle, R., Rigo, S. J., Marques, L. B., de Miranda Coelho, J. A. P., \& Jaques, P. A. (2020). The impact of gamification on students' learning, engagement and behavior based on their personality traits. Smart Learning Environments, 7(1), 1-11. https://doi.org/10.1186/s40561-019-0098-x

Stavredes, T., \& Herder, T. (2014). A guide to online course design: Strategies for student success. Wiley.

Stoyanova, M., Tuparova, D., \& Samardzhiev, K. (2017). Impact of motivation, gamification and learning style on students' interest in Maths classes-A Study in 11 high school grade. In International conference on interactive collaborativelearning (pp. 133-142). Springer, Cham. https://doi.org/10.1007/978-3-319-73204-6_17

Stoyanova, M., Tuparova, D., \& Samardzhiev, K. (2016). Gamification in 11 th grade mathematics lessons-One possible interactive approach. In International conference on interactive collaborative learning (pp. 41-53). Springer, Cham. https://doi.org/10.1007/978-3-319-50340-0_4

Sumtsova, O., Aikina, T., Bolsunovskaya, L., Phillips, C., Zubkova, O., \& Mitchell, P. (2018). Collaborative learning at engineering universities: Benefits and challenges. International Journal of Emerging Technologies in Learning (IJET), 13(1), 160-177. https://doi.org/10.3991/ijet.v13i01.7811

Sunzuma, G., \& Maharaj, A. (2019). Teacher-related challenges affecting the Integration of ethnomathematics approaches into the teaching of geometry. EURASIA Journal of Mathematics, Science and Technology Education, 15(9), em1744. https://doi.org/10.29333/ejmste/108457

Takele, M. (2020). Implementation of active learning methods in mathematics classes of Woliso town primary schools, Ethiopia. International Journal of Science and Technology Education Research, 11(1), 1-13. 
Tangram Blackline Masters (1994).

Tchoshanov, M. (2011). Building students' mathematical proficiency: Connecting mathematical ideas using the tangram. Learning and Teaching Mathematics, 10, 16-23.

Ting, F. S. T., Lam, W. H., \& Shroff, R. H. (2019). Active learning via problem-based collaborative games in a large mathematics university course in Hong Kong. Education Sciences, 9(3), 172.

Udjaja, Y., Guizot, V. S., \& Chandra, N. (2018). Gamification for elementary mathematics learning in Indonesia. International Journal of Electrical and Computer Engineering (IJECE), 8(5), 3860-3865. https://doi.org/10.11591/ijece.v8i5. pp3860-3865

van Geert, P., \& Steenbeek, H. (2005). The dynamics of scaffolding. New Ideas in Psychology, 23(3), 115-128.

van Hiele, P. M. (1999). Developing geometric thinking through activities that begin with play. Teaching Children Mathematics, 6, 310-316.

Vygotsky, L. (1978). Interaction between learning and development. Readings on the Development of Children, 23(3), 34-41.

Wiersum, K. (2012). Teaching and learning mathematics through games and activities. Acta Electrotechnica Et Informatica, 12(3), 23-26. https://doi.org/10.2478/v10198-012-0026-2

Xiang, O. C., Ann, T. T., Hui, C. Y., \& Yew, L. T. (2014). Effectiveness of gamification in vocational technical education. European Conference on Games Based Learning, 2, 636-644.

\section{Publisher's Note}

Springer Nature remains neutral with regard to jurisdictional claims in published maps and institutional affiliations.

\section{Submit your manuscript to a SpringerOpen ${ }^{\circ}$} journal and benefit from:

- Convenient online submission

- Rigorous peer review

- Open access: articles freely available online

- High visibility within the field

- Retaining the copyright to your article

Submit your next manuscript at $\gg$ springeropen.com 